\title{
Kinetics of the Reversible Transformation of 2,3-Dioxogulonic Acid into its Enol as a Function of the $\mathrm{pH}$ of the Medium
}

\author{
J. Zuluaga and P. Martínez* \\ Departamento de Investigaciones Químicas I. Centro Coordinado del C.S.I.C. y la Universidad \\ Autónoma de Madrid
}

Z. Naturforsch. 33a, 1184-1189 (1978); received June 27, 1977

2,3-dioxogulonic acid and the disodium salt of its enol were synthesised, isolated and identified both chemically and spectroscopically. A kinetic study was carried out on its equilibrium by means of the "stopped flow" method for rapid processes, and the rate constants for the forward and backward reaction were determined as a function of the $\mathrm{pH}$ of the medium. The kinetic coefficients involved, equilibrium constant and Gibbs free energies were also determined.

\section{Introduction}

An optical isomer of ascorbic acid or vitamin $\mathrm{C}$ is araboascorbic acid (A), which has a lactone structure with an endiol group [1]. The oxidation $[2,3,4]$ of this acid produces dehydroascorbic acid $\left(\mathrm{A}^{\prime}\right)$ which is very reactive in an aqueous solution; a progressive decrease in the $\mathrm{pH}$ and specific rotation $[5,6]$ is observed and is a consequence of the rupture of the lactone ring during the formation of 2,3-dioxogulonic acid (B) which, in turn, enolizes producing the $d i$ sodium salt $(\mathrm{C})$ :<smiles>O=C1OC(C(O)CO)C(O)=C1O</smiles>

(A)

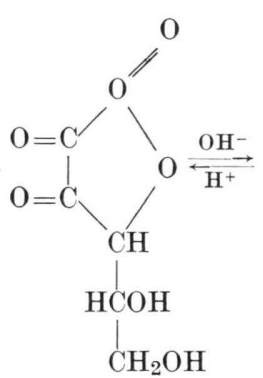

$\left(\mathrm{A}^{\prime}\right)$<smiles>O=C(O)C(=O)C(=O)C(O)C(O)CO</smiles>

(B)

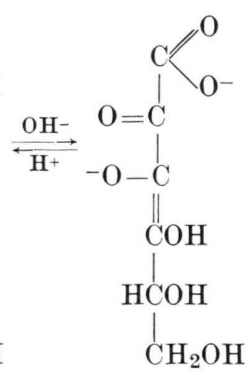

(C)
* Correspondence to be addressed to Prof. Dr. Pablo Martínez, Facultad de Ciencias C-II, Universidad Autónoma, Madrid 34, Spain. or. Gustav-Adolf-Str. 34, D-6450 Hanau, Germany.
From a kinetic point of view, the overall reaction with the implied species can be represented by:

$$
\mathrm{A} \rightarrow \mathrm{A}^{\prime} \underset{k_{2}}{\stackrel{k_{1}}{\rightleftarrows}} \mathrm{B} \underset{k_{4}}{\stackrel{k_{3}}{\rightleftarrows}} \mathrm{C} \text {. }
$$

As yet, no quantitative study has been carried out on the kinetic aspect of this mechanism in a homogeneous phase. Penney and Zilva [7] have studied the $\mathrm{A}^{\prime} \rightleftarrows \mathrm{B}$ equilibrium both qualitatively and semiquantitatively, but not kinetically.

The present study is centred on the $\mathrm{B} \rightleftarrows \mathrm{C}$ equilibrium, where the rate constants in both directions, $k_{3}$ and $k_{4}$, are measured with regard to the $\mathrm{pH}$ of the medium. The kinetic coefficients $k_{0}, k_{\mathrm{OH}^{-}}, \overleftarrow{k}_{0}$, $k_{\mathrm{H}^{+}}$are determined, together with the equilibrium constant $K$ and the Gibbs free energy $\Delta G^{0}$.

In order to carry out this study, substances B and $\mathrm{C}$ were synthesised, isolated and identified both chemically and spectroscopically. These substances were subjected to a complete kinetic study by means of the "stopped flow" technique for rapid reactions using a "Durrum Rapid Kinetics Systems D-100".

\section{Synthesis and Identification}

The Kenyon and Munro [6] method, modified and simplified by us [8], was used to synthesise the 2,3-dioxogulonic acid and the disodium salt of the enol:

$8 \mathrm{gm}$ of pure araboascorbic acid and $12 \mathrm{gm}$ of resublimated iodine were stirred in $75 \mathrm{ml}$ of methanol. Lead carbonate was added until the mixture was decolourised. The resulting mixture was filtered and washed with methanol. Any remaining traces of lead in the solution were precipitated by bubbling through $\mathrm{H}_{2} \mathrm{~S}$. The $\mathrm{PbS}$ precipitate was removed from the methanol solution of the dehydroascorbic 


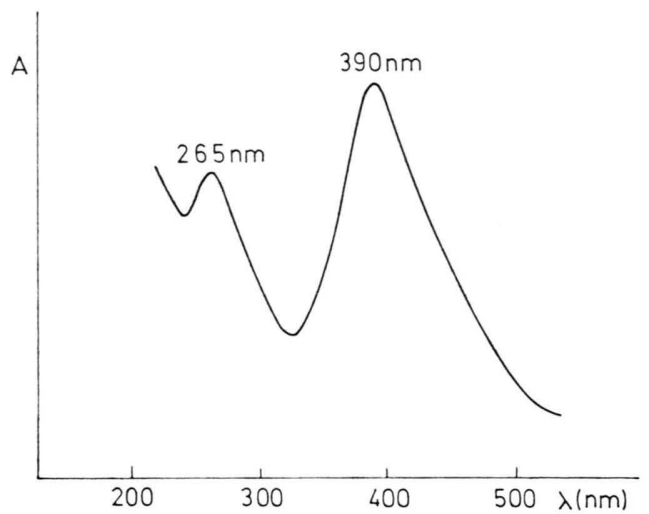

Fig. 1. Absorption spectrum of substance B (2,3-dioxogulonic acid).

acid (m.p. $225^{\circ} \mathrm{C}$ ) by a vacuum filtration. To the remaining solution, a solution of $1.6 \mathrm{gm}$ of $\mathrm{NaOH}$ in $100 \mathrm{ml}$ of methanol was added whilst constantly stirring. A yellow precipitate of 2,3-dioxogulonic acid (m.p. $282^{\circ} \mathrm{C}$ ) was obtained. When continuing to add the $\mathrm{NaOH}$ in methanol, an orange precipitate was obtained and resulted to be the disodium salt of the enol of the 2,3-dioxogulonic acid (m.p. $208^{\circ} \mathrm{C}$ ).

In order to identify substances B and C, obtained by the above process, these were transformed into their corresponding 2,4-dinitrophenylhydrazones using 2,4-dinitrophenylhydrazine alcohol. For the derivative of $\mathrm{B}$, a melting point of $281^{\circ} \mathrm{C}$ was obtained (bibliography [7] gives $282^{\circ} \mathrm{C}$ ) and for C, $206^{\circ} \mathrm{C}$ (bibliography $[6,9]: 208^{\circ} \mathrm{C}$ ). Likewise, absorption spectra were taken of substances B and C using a Beckman spectrophotometer (UV and visible) with an analytical power of \pm 0.001 absorption

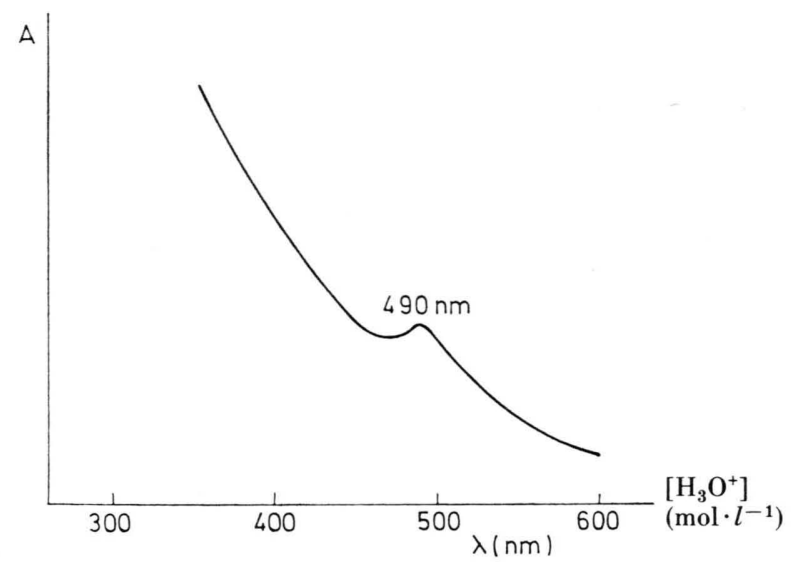

Fig. 2. Absorption spectrum of substance $\mathrm{C}$ (disodium salt of the 2,3-dioxogulonic acid).

units. The resulting spectra, with their corresponding peaks of maximum absorption, are given in Figures 1 and 2. The values coincide with those tabulated $[10,11]$ for 2,3-dioxogulonic acid $(390 \mathrm{~nm})$ and the disodium salt of its enol $(490 \mathrm{~nm})$.

\section{Description of Kinetic Method}

The kinetic scheme studied is made up of rapid chemical reactions and therefore the "stopped flow" technique is very appropriate. Use was made of a "Durrum Rapid Kinetics Systems D-100" which can be used for both "stopped flow" and "temperature jump". Figure 3 gives a general scheme of the apparatus. From the reservoir syringes (1) the reagents are injected through to the drive syringes (2) which are struck by a flow actuator ram plunger (nitrogen at 3-4 atm.) and pass through the chan-

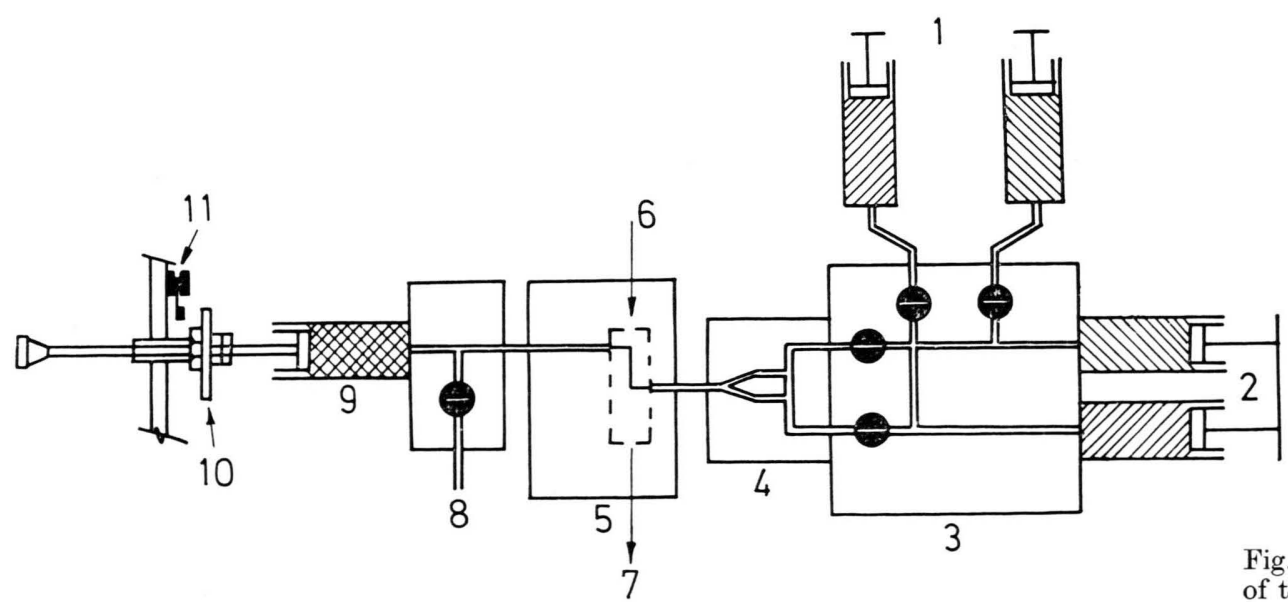

Fig. 3. A general scheme of the apparatur. 
nels of the valve block (3) to the mixing chamber (4) where the reaction takes place. The reaction is observed by the absorption produced in the monochromatic light (6) which, after passing through the reaction zone impinges on a photomultiplier tube (7). The reaction products are eliminated by means of a drain valve (8). The stop syringe (9) limits the injection flow to a both fixed and small reaction volume. The movement of this syringe displaces the contact plate (10), which in turn actuates a trigger switch (11) that commences the registration of the absorbance or transmittance signals in the oscilloscope from the reaction chamber. The mixing chamber is made up of three modules: a photomultiplier power supply, a log buffer amplifier and a pneumatic flow actuator control unit.

The variables that can be controlled in the "stopped flow" are: the wavelength, slit width, temperature, time constant, volume of sample, sensitivity and reaction components.

\section{Measurements and Results}

With the rapid technique of the "stopped flow" the formation or decomposition of a substance is followed spectrophotometrically as a function of time. It is therefore possible to determine individual rate constants.

The kinetic scheme can be represented as:

$$
\mathrm{B}+\mathrm{OH}^{-} \underset{k_{4}}{\stackrel{k_{3}}{\rightleftarrows}} \mathrm{C}+\mathrm{H}_{3} \mathrm{O}^{+} .
$$

The working temperature was maintained at $22^{\circ} \mathrm{C}$.

The kinetic study was begun by considering the transformation of the disodium salt of the enol form of 2,3-dioxogulonic acid, i.e. the process $\mathrm{C} \rightarrow \mathrm{B}$. According to (2), this process is favoured by an acid medium, therefore, for this study, a $\mathrm{pH}$ range of 0.44 to 1.46 was used. At lower $\mathrm{pH}$ 's, the process became too slow for the stopped flow method. Thus, the influence of the $\mathrm{pH}$ over the reaction rate will also be studied.

The step considered:

$$
\mathrm{C}+\mathrm{H}_{3} \mathrm{O}^{+} \stackrel{k_{4}}{\rightarrow} \mathrm{B}+\mathrm{OH}^{-}
$$

is a second order reaction, kinetically speaking. If, however, the $\mathrm{H}_{3} \mathrm{O}^{+}$concentrations are high in comparison with those of substance $\mathrm{C}$, the process is converted into a pseudo-first order one. As the concentration of $\mathrm{C}$ is maintained at $1.0 \cdot 10^{-3} \mathrm{M}$, this condition is fulfilled when the $\mathrm{H}_{3} \mathrm{O}^{+}$concentration is greater than $2 \cdot 10^{-2} \mathrm{M}$ i.e. at least 20 times larger. In the $\mathrm{pH}$ range under study, the condition is easily fulfilled. The reaction was also carried out with equal concentrations of $\mathrm{C}$ and $\mathrm{H}_{3} \mathrm{O}^{+}$, so that the true second order rate constant, $k_{4} \mathrm{II}$, could be determined. With an excess of $\mathrm{H}_{3} \mathrm{O}^{+}$, the rate constant obtained is a first order one, $k_{4} \mathrm{I}$.

The $\mathrm{pH}$ 's used were: $0.44 ; 0.60 ; 0.75 ; 0.94 ; 1.03$; 1.20 and 1.46, and were obtained with $\mathrm{HCl}$ p.a. from Merck, to a second decimal point with a Beckman $\mathrm{pH}$-meter, Century SS-1 model, with a precision of $\pm 0.005 \mathrm{pH}$ units.

As the potentiometric method provides proton activitites, and it is necessary to study the relationship between $k_{4}$ and the true proton concentration, the $a_{\mathrm{H}^{+}}$were transformed into $c_{\mathrm{H}^{+}}$, by using the respective activity coefficients $f_{\mathrm{H}^{+}}$obtained from tables.

When the reaction is produced using the stopped flow method, there appears, at the oscilloscope, the absorption curve of the substance of which the wavelength is measured, as a function of the time. This change in absorption is a kinetic measurement of the process. From photographs of these curves at the oscilloscope, the average absorption values, $\bar{A}$, were obtained together with their corresponding $\log _{\mathrm{e}} \bar{A}$, as a function of the time and at varying pH's. See example in Figures 4 and 5.

Table I gives the results obtained for the first order rate constants obtained $k_{4} \mathrm{I}$ for the step $\mathrm{C} \rightarrow \mathrm{B}$ at the different $\mathrm{pH}$ 's studied. Correction by the

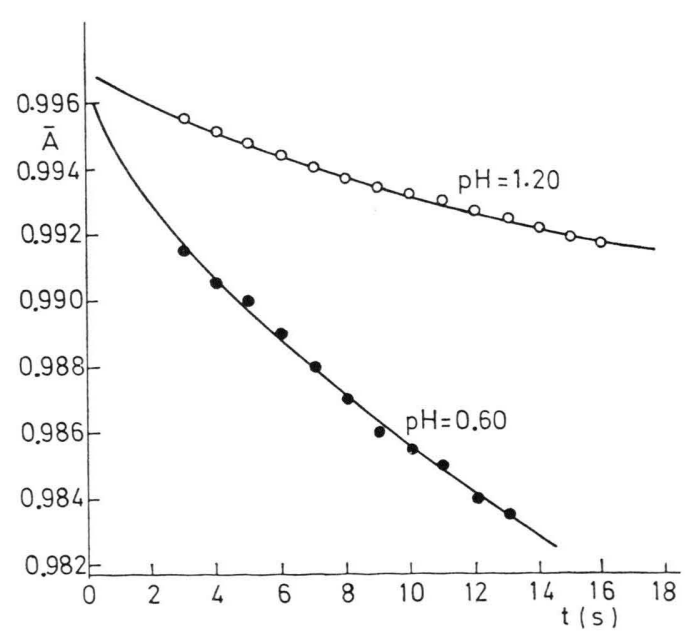

Fig. 4. Decrease in average absorbance of substance $\mathrm{C}$ with time in the kinetic steps $\mathrm{C} \rightarrow \mathrm{B}$ at various acid $\mathrm{pH}$ 's. 


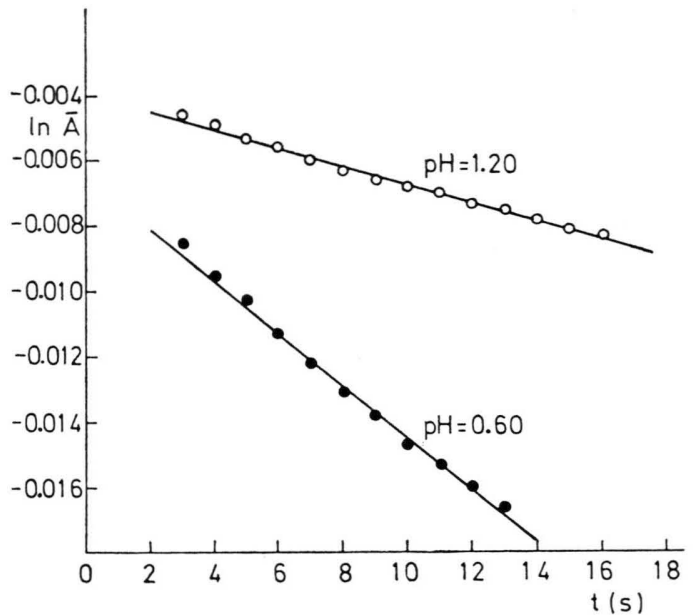

Fig. 5. Linear relationship between $\log _{\mathrm{e}} A$ and $t$ in kinetic step $\mathrm{C} \rightarrow \mathrm{B}$ as a function of medium.

least squares method was carried out by a HewlettPackard calculator. The relative error in experimental measurements is approximately $5 \%$.

Figure 6 gives the plot of these constants versus the proton concentration of the medium. As is observed there exists a linear relationship of the type:

$$
k_{4}{ }^{\mathrm{I}}=\overleftarrow{k}_{0}+k_{\mathrm{H}^{+}} c_{\mathrm{H}^{+}} .
$$

With a least squares correction of this experimental relationship, the following is obtained for the kinetic coefficients:

$$
\begin{aligned}
\overleftarrow{k}_{0} & =1.3 \cdot 10^{-4} \mathrm{~s}^{-1}, \\
k_{\mathrm{H}^{+}} & =2.4 \cdot 10^{-3} \mathrm{l} \cdot \mathrm{mol}^{-1} \mathrm{~s}^{-1} .
\end{aligned}
$$

Considering the kinetic step $\mathrm{B} \rightarrow \mathrm{C}$ :

$$
\mathrm{B}+\mathrm{OH}^{-} \rightarrow \mathrm{C}+\mathrm{H}_{3} \mathrm{O}^{+} \text {. }
$$

A sufficiently high concentration of $c_{\mathrm{OH}^{-}}$is used so that the process can also be considered kinetically here as a first order one. Concentrations of

$$
c_{\mathrm{B}}=1.0 \cdot 10^{-3} \mathrm{~mol} / \mathrm{l}
$$

Table I. First order rate constants for the step C $\rightarrow$ B as a function of the $\mathrm{pH}$.

\begin{tabular}{lll}
\hline $\mathrm{pH}$ & $C_{\mathrm{H}+}(\mathrm{M})$ & $k_{4}^{\mathrm{I}} \cdot 10^{4}\left(\mathrm{~s}^{-1}\right)$ \\
\hline 0.44 & 0.475 & 12.4 \\
0.60 & 0.328 & 9.4 \\
0.75 & 0.230 & 6.6 \\
0.94 & 0.145 & 4.8 \\
1.03 & 0.116 & 4.1 \\
1.20 & 0.077 & 3.1 \\
1.46 & 0.041 & 2.9 \\
\hline
\end{tabular}

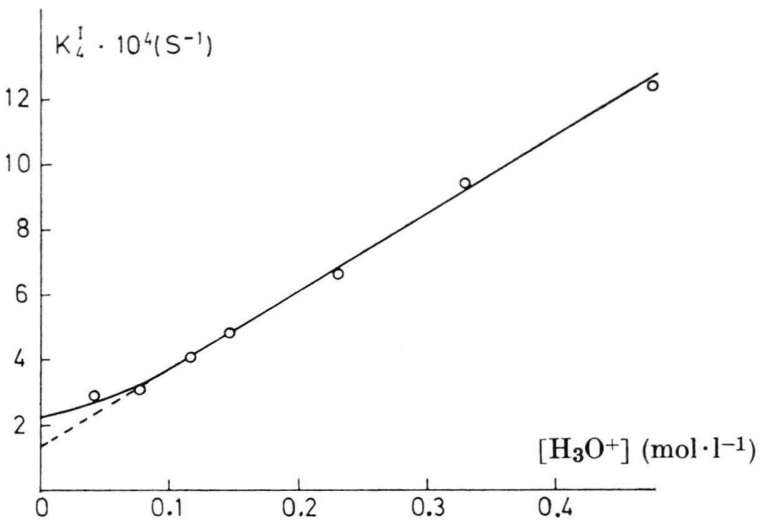

Fig. 6. Determination of kinetic coefficients $\overleftarrow{k}_{\mathrm{O}}$ and $k_{\mathrm{H}^{+}}$in chemical step $\mathrm{C} \rightarrow \mathrm{B}$.

and

$$
c_{\mathrm{OH}^{-}}=0.038 \text { to } 0.304 \mathrm{~mol} / \mathrm{l}
$$

are used corresponding to $\mathrm{pH} 12.51$ to 13.34 . These basic $\mathrm{pH}$ 's were adjusted with $\mathrm{NaOH}$ p.a. from Merck and using the previously mentioned Beckman $\mathrm{pH}$-meter, having converted the $a_{\mathrm{OH}^{-}}$into $c_{\mathrm{OH}^{-}}$by means of $f_{\mathrm{OH}^{-}}$from tables [12]. The results obtained for $k_{3} \mathrm{I}$ are given in Table II and have an approximate error of $5 \%$.

Figure 7 shows the variation of $k_{3}{ }^{\mathrm{I}}$ with $c_{\mathrm{OH}^{-}}$ and, as is observed, the following linear relationship exists :

$$
k_{3} \mathrm{I}=\vec{k}_{0}+k_{\mathrm{OH}^{-}} c_{\mathrm{OH}^{-}} .
$$

A least squares correction of this linear relationship gives the following values for the kinetic coefficients :

$$
\begin{aligned}
\vec{k}_{0} & =1.2 \cdot 10^{-2} \mathrm{~s}^{-1}, \\
k_{\mathrm{OH}^{-}} & =7.0 \cdot 10^{-2} \mathrm{l} \cdot \mathrm{mol}^{-1} \cdot \mathrm{s}^{-1} .
\end{aligned}
$$

A kinetic study was also carried out on reactions (3) and (5) with equal concentrations of $\mathrm{B}$ and $\mathrm{OH}^{-}$, and $\mathrm{C}$ and $\mathrm{H}_{3} \mathrm{O}^{+}$, in order to determine the true

Table II. First order rate constants for the step B $\rightarrow$ C as a function of the $\mathrm{pH}$.

\begin{tabular}{lll}
\hline $\mathrm{pH}$ & $c_{\mathrm{OH}^{-}}(\mathrm{M})$ & $k_{3}^{\mathrm{I}} \cdot 10^{2}\left(\mathrm{~s}^{-1}\right)$ \\
\hline 13.34 & 0.304 & 3.4 \\
13.30 & 0.278 & 3.2 \\
13.25 & 0.243 & 2.9 \\
13.20 & 0.214 & 2.6 \\
13.11 & 0.171 & 2.5 \\
12.98 & 0.124 & 2.1 \\
12.81 & 0.081 & 1.8 \\
12.51 & 0.038 & 1.3 \\
\hline
\end{tabular}




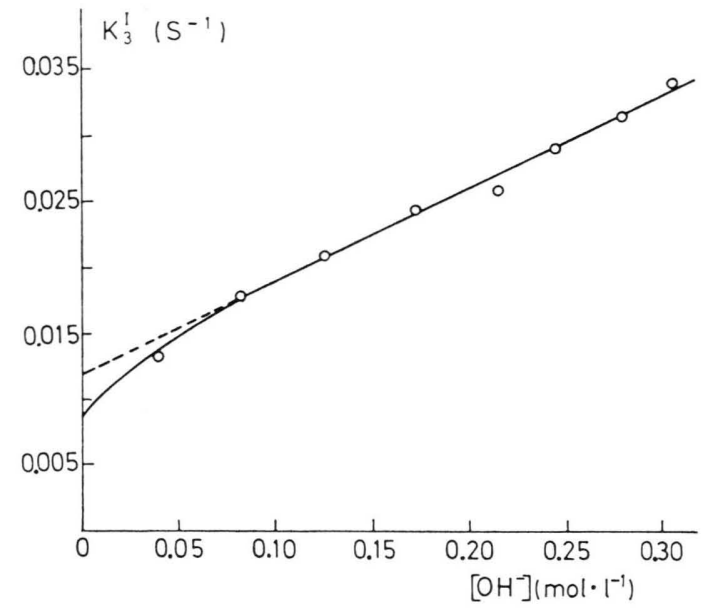

Fig. 7. Determination of kinetic coefficients $\overleftarrow{k}_{\mathrm{O}}$ and $k_{\mathrm{OH}^{-}}$ in chemical step $\mathrm{B} \rightarrow \mathrm{C}$.

second order rate constants $k_{3} \mathrm{II}$ and $k_{4} \mathrm{II}$ and to determine the constant $K$ of the equilibrium (2).

With equal concentrations of reagents, these second order kinetic processes follow the rate law:

$$
1 / c=1 / c_{0}+k t .
$$

Figures 8 and 9 give the linear relationships observed under these conditions, for processes (3) and (5) respectively. A least squares correction of the experimental straight lines give the following values for the second order rate constants:

$$
\begin{aligned}
& k_{3} \mathrm{II}=2.1 \cdot 10^{-2} \mathrm{l} \cdot \mathrm{mol}^{-1} \mathrm{~s}^{-1}, \\
& k_{4} \mathrm{II}=5.4 \cdot 10^{-4} \mathrm{l} \cdot \mathrm{mol}^{-1} \mathrm{~s}^{-1} .
\end{aligned}
$$

From the equation:

$$
K=k_{3}{ }^{\mathrm{II}} / k_{4} \mathrm{II}
$$

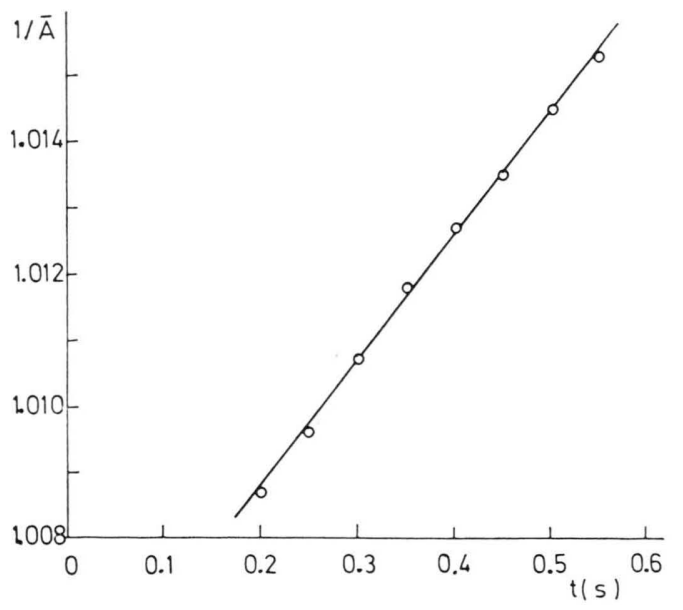

Fig. 8. Determination of 2 nd order rate constant $\mathrm{K}_{3}^{\mathrm{II}}$ of kinetic process $\mathrm{B}+\mathrm{OH}^{-} \rightarrow \mathrm{C}+\mathrm{H}_{3} \mathrm{O}$.

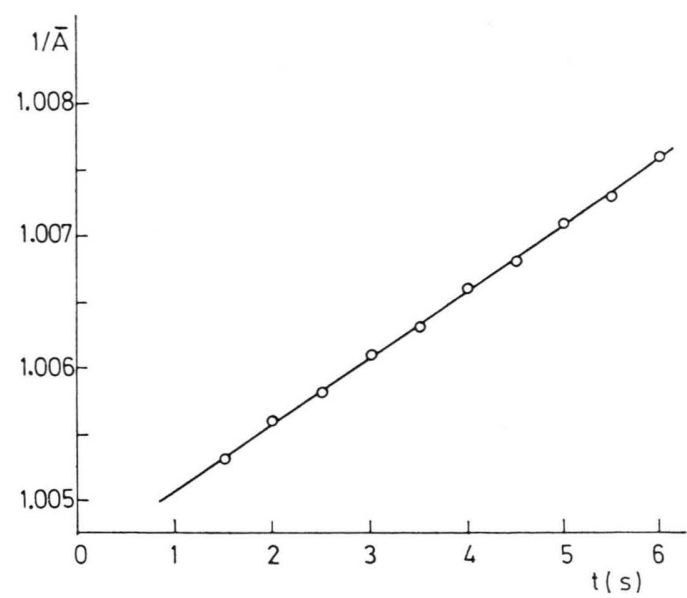

Fig. 9. Determination of 2 nd order rate constant $\mathrm{K}_{4}^{\mathrm{II}}$ of kinetic process $\mathrm{C}+\mathrm{H}_{3} \mathrm{O}^{+} \rightarrow \mathrm{B}+\mathrm{OH}^{-}$.

the equlibrium constant of (2) results to be:

$$
K=38.9 \text {. }
$$

From the thermodynamic relationship:

$$
\Delta G^{0}=-R T \log _{\mathrm{e}} K
$$

we obtain for the Gibbs free energy:

$$
\Delta G_{295}^{0}=-2.15 \mathrm{kcal} \cdot \mathrm{mol}^{-1} \text {. }
$$

There is an overall error of approximately $5 \%$ in all these values.

At neutral $\mathrm{pH}$ the relationship of the kinetic coefficients $\vec{k}_{0} / \overleftarrow{k}_{0}$, should also give the equilibrium constant, $K$. However, this value for $K$ was found to be somewhat high, if the linear relationships between $k_{3} \mathrm{I}$ and $c_{\mathrm{OH}^{-}}, k_{4} \mathrm{I}$ and $c_{\mathrm{H}^{+}}$are admitted up to neutral pH. As is seen in Fig. 6 and 7, however, for low values of $c_{\mathrm{OH}^{-}}$and $c_{\mathrm{H}^{+}}$the linear relationships are no longer valid, and slightly curved segments appear fom which values can be estimated at

$$
\vec{k}_{0} \cong 8.5 \cdot 10^{-3} \mathrm{~s}^{-1} \text { and } \quad \vec{k}_{0} \cong 2.3 \cdot 10^{-4} \mathrm{~s}^{-1} .
$$

Therefore $K=\vec{k}_{0} / \overleftarrow{k}_{0} \cong 37$; this value coinciding with that previously obtained. In order to obtain the exact values of $\vec{k}_{0}$ and $\overleftarrow{k}_{0}$ kinetic experiments would have to be carried out with very low concentrations of $\mathrm{OH}^{-}$and $\mathrm{H}_{3} \mathrm{O}^{+}$.

\section{Discussion}

As has been observed, the experimental first order rate constants, both for steps $\mathrm{B} \rightarrow \mathrm{C}$ and $\mathrm{C} \rightarrow \mathrm{B}$, 
clearly depend on the $\mathrm{pH}$ of the medium. These constants can be expressed in terms of linear relationships which imply kinetic coefficients; one being a catalytic second order coefficient $\left(k_{\mathrm{H}^{+}}, k_{\mathrm{OH}^{-}}\right)$and the other non catalytic and first order $\left(\overleftarrow{k}_{0}, \vec{k}_{0}\right)$ according to the following empirical expressions:

$$
\begin{aligned}
k_{3} \mathrm{I}=k_{0} & +k_{\mathrm{OH}^{-}} c_{\mathrm{OH}^{-}}=1.2 \cdot 10^{-2} \\
& +7.0 \cdot 10^{-2} \cdot c_{\mathrm{OH}^{-}}\left(\mathrm{s}^{-1}\right), \\
k_{4} \mathrm{I}=k_{0} & +k_{\mathrm{H}^{+}} c_{\mathrm{H}^{+}}=1.3 \cdot 10^{-4} \\
& +2.4 \cdot 10^{-3} \cdot c_{\mathrm{H}^{+}}\left(\mathrm{s}^{-1}\right)
\end{aligned}
$$

where $c_{\mathrm{OH}^{-}}$and $c_{\mathrm{H}^{+}}$are expressed in $\mathrm{mol} \cdot \mathrm{1}^{-1}$.

The true second order rate constants, $k_{3} \mathrm{II}$ and $k_{4} \mathrm{II}$ obtained with equal concentrations of reagents, clearly demonstrate that the equilibrium between 2,3-dioxogulonic acid and the disodium salt of its enol form is displaced very much towards the enol form in $97 \%$. In agreement with this fact, the

[1] E. Schauenstein, Monats. f. Chemie 78, 487 (1948).

[2] N. M. Taqui and A. E. Martell, J. Am. Chem. Soc. 89, 1417 (1967).

[3] Y. Ogata, Y. Kosugi, and T. Marimoto, Tetraedron 24, 4057 (1968).

[4] M. Domínguez and A. Aldaz, J. Electroanal. Chem. 68, 345 (1976).

[5] E. G. Ball, J. Biological Chem. 118, 219 (1937).

[6] J. Kenyon and N. Munro, J. Chem. Soc. 158, (1948).

[7] J. R. Penney and S. S. Zilva, Biochem. J. 37, 39, 403 (1943). equilibrium constant has a highly positive value $(K \cong 39)$ and the Gibbs free energies are negative $\left(\Delta G^{0} \simeq-2.2 \mathrm{kcal} \cdot \mathrm{mol}^{-1}\right)$.

In the range of $\mathrm{pH}$ 's that are neither very acid nor basic i.e. $\mathrm{pH} 4$ to 10 , the relationship between the non catalytic kinetic coefficients, $\vec{k}_{0} / \overleftarrow{k}_{0}$ gives a value in agreement with this for the equilibrium constant $K$ of the process, as theoretically expected. However, in order to confirm the loss of linearity of $k_{3}{ }^{\mathrm{I}}$ vs. $c_{\mathrm{OH}^{-}}$and of $k_{4}{ }^{\mathrm{I}}$ vs. $c_{\mathrm{H}^{+}}$at low concentrations of $\mathrm{OH}^{-}$and $\mathrm{H}_{3} \mathrm{O}^{+}$, further kinetic experiments are necessary in the $\mathrm{pH}$ range and will be carried out in later studies.

\section{Acknowledgements}

This study was supported by the Comisión Asesora de Investigación Científica y Técnica, (Madrid).

[8] J. Zuluaga, Tesina de Licenciatura, Facultad de Ciencias, Universidad Autónoma, Madrid (1977).

[9] R. Q. Brewster, Curso práctico de Química Orgánica, Ed. Alhambra, Madrid (1970).

[10] N. Paech, Moderne Methoden der Pflanzenanalyse, Springer-Verlag, Berlin (1955).

[11] B. Bielski and A. Allen, J. Am. Chem. Soc. 92, 3793 (1970).

[12] S. Glastone, Termodinámica para químicos. Ed. Aguilar, Madrid (1972). 